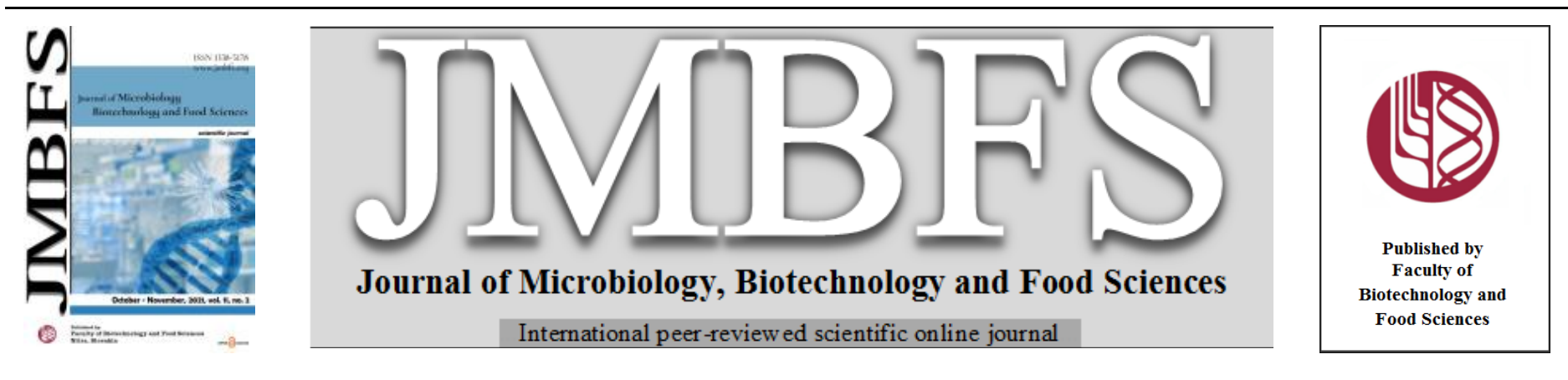

\title{
IMMOBILIZATION OF PROBIOTIC CULTURES WITH ENTEROSORBENTS BASED ON HIGHLY DISPERSED SILICA
}

\author{
Svetlana Danylenko ${ }^{1 *}$, Irina Romanchuk ${ }^{1}$, Lolita Marynchenko ${ }^{2}$, Tanya Kryzhska ${ }^{3}$, Olena Nizhelska ${ }^{4}$, Oksana Potemska $^{1}$, Myroslav \\ Khonkiv $^{1,5}$ and Daria Kyseliuk ${ }^{2}$
}

Address(es): Dr. Svetlana Danylenko,

${ }^{1}$ Institute of Food Resources of NAAS, Department of Biotechnology, Yevhena Sverstiuka 4a., Kyiv 02002, Ukraine, +38(044)5171737.

${ }^{2}$ Igor Sikorsky Kyiv Polytechnic Institute, Department of bioinformatics, Peremohy 37, Kyiv, Ukraine, 03056.

${ }^{3}$ Sumy National Agrarian University, Gerasim Kondratiev 160, Sumy 40000, Ukraine.

${ }^{4}$ The Scientific and Training Center "Physical and Chemical Material Science" of NAS, Nauky 46., Kyiv 03028, Ukraine.

${ }^{5}$ National University of Food Technologies, Department of biotechnology and microbiology, Volodymyrska 68., Kyiv 01601, Ukraine.

*Corresponding author: biotech_ipr@ukr.net

https://doi.org/10.15414/jmbfs.3334

\section{ARTICLE INFO}

Received 24. 6. 2020

Revised 26. 4. 2021

Accepted 7. 5. 2021

Published 1. 10. 2021

Regular article

open $\partial_{\text {access }}$

\begin{abstract}
An important effectiveness factor of probiotic therapy is the survival of cells in the gastrointestinal tract and their integration into the intestinal biofilm. The possibility of creating complex preparations of enterosorbent-probiotic on the basis of dry highly dispersed silica and methyl-silicic acid hydrogel has been investigated. The survival of Streptococcus thermophilus and Bifidobacterium longum monocultures in the composition of lyophilized complex preparations, in particular under the simulated conditions of the gastrointestinal tract, was studied.

The rheological and biotechnological parameters of yoghurt fermented with S. thermophilus IMV B-7249 strain immobilized in a hydrogel were evaluated. It was determined that the functional state of the culture immobilized in highly dispersed silica remained corresponded to the proper technological parameters of sour-milk yoghurt, and the effective viscosity and stability of the product increased. This makes it possible to recommend such a preparation for a use not only for enteral use but also for the production of fermented milk products.
\end{abstract}

Keywords: probiotics, high-dispersed silica, survival, fermented milk product, immobilization

\section{INTRODUCTION}

One of the areas for the treatment of dysbiosis is the use of probiotic cultures of microorganisms used as fermentation cultures in fermented milk drinks, or lyophilized forms of drugs for oral taking. Another means of detoxification is enterosorption by fine silica. Nanoporous silica for controlled drug and cell delivery is promising given their peroral bioavailability (Voronin, et al., 2016; Florek, Caillard, \& Kleitz, 2017). In addition, nanosized $\mathrm{SiO}_{2}$ is an accessible, non-toxic, non-traumatic nanomaterial (Diab, et al., 2017). However, it should be acknowledged that in reality the nature of the interactions between nanoparticles and living cells is more complex and depends, in particular, on the ratio of "surface area - volume" of nanoparticles and the ratio of surface areas of nanoparticles and cells [Leonenko \& Leonenko, 2020].

For nanosilicon adsorbed on the cell surface (not vice versa!) various mechanisms of interaction of silica with cell walls and cell membranes have been proposed, in particular, mechanisms of erythrocyte hemolysis (Gerashchenko, 2009; Fubini, 1998; Nolan \& Langer, 1997; Dalal, et al., 1990). According to them, hemolytic activity can be caused by bonds between negatively charged silanol groups and membrane components. It has also been shown that hydrophobic silica modified with methyl groups did not adversely affect cells (Gerashchenko, 2009). Surface glycoproteins contain negatively charged sialic acid residues, which adversely affects adsorption of nanosilica. As a result of further research, the theory of selectivity of hemolytic activity of nanosilica, which consists of the difference in the density of the negative charge on the cell surface, was published. Thus, older cells have less negatively charged sialic acid residues on the surface, and therefore are subject to hemolysis much more often than young erythrocytes (Dalal, et al., 1990). It follows that for better preservation, the culture must be young.

It is shown that the adsorption of nanosized silica is characteristic of both grampositive and gram-negative bacteria (Gerashchenko, 2009). The data obtained after treatment of cells with substances that destroy the membrane indicate the importance of membrane proteins in the mechanism of binding to nano-silica This is evidenced by a decrease in the membrane-tropic activity of the sorbent after modification of the membranes by adding trypsin, lysozyme and EDTA to the cell suspension.

It was described complex drugs of 2-3 generations, which combine the properties of medicinal substances (antiseptics, rehydrators, enzymes, antiarrhythmic drugs) with enterosorbents to model the pharmacokinetics and biotransformation of the active agent (Gorbyk, et al., 2008).

Recent studies have acknowledged that the toxicity of nanomaterials to cells depends largely not only on the chemical nature, but also on the size, shape, concentration, way of penetration into the body and a combination of these factors. For example, for nanosized $\mathrm{SiO}_{2}$ the $\mathrm{LD}_{50}$ was $4638 \mu \mathrm{g} / \mathrm{kg}$, while for microdispersed silica it was $10000 \mu \mathrm{g} / \mathrm{kg}$. In addition, spherical particles had less damaging effects than elongated ones [Leonenko \& Leonenko].

The effect of probiotics Lactobacillus bulgaricus immobilized on sorbents based on activated carbon "Sorbex" and "Sums", as well as their storage by cryopreservation was also studied. The effect of immobilized probiotics on rats with chemotherapeutic dysbiosis was significantly better than the effect of native probiotics, enterosorbents and probiotic-sorbent mixtures. This was evidenced by the faster return of the microflora of the colon to normal and the elimination of pathogenic microflora. Cryopreservation of complexes of sorbent and probiotic did not affect the ability of the latter to counteract pathogens, as well as their sensitivity to antibiotics and hydrochloric acid. Immobilized probiotics were stored at temperatures of $-80 \ldots-196^{\circ} \mathrm{C}$, and the number of "carrier-cell" complexes decreased slightly (Babinets, 2012).

Thus, the scientific search for the creation of complex drugs enterosorbentprobiotic is a promising area, which should take into account the complex nature of the interactions of highly dispersed materials with living cells.

The aim of our research was to study the possibility of sorption of probiotic cultures on samples of dry highly dispersed silica and methyl silicic acid hydrogels and to assess their functional status by technological parameters of yoghurt fermented on the basis of strain S. thermophilus IMB B-7249. 


\section{MATERIALS AND METHODS}

\section{Strains and Growth Conditions}

The objects of the study were collection monocultures of $S$. thermophilus IMV B 7249, B. longum IMV 7033, which are used to obtain fermented dairy products. Pure cultures were maintained at a temperature $(38-41){ }^{\circ} \mathrm{C}$ (thermophilic species) lactic acid bacteria in MRS broth (Mann, Rogoza, Sharpe), bifidobacteria - in Blaurock medium.

Accumulation of bacterial mass of cultures was performed at a temperature of 37 $\pm 2^{\circ} \mathrm{C}$ for $14-15 \mathrm{~h}$ with periodic neutralization of the culture medium of MPC with $25 \%$ aqueous ammonia solution to an active acidity of $6.6 \pm 0.1 \mathrm{units} \mathrm{pH}$.

The obtained biomass was separated from the culture fluid by centrifugation at $15000 \mathrm{~min}^{-1}$ and temperature $(8 \pm 2){ }^{\circ} \mathrm{C}$.

Preparations of immobilized cells for experiments were prepared as follows. 100 $\mathrm{g}$ sorbent and $1 \mathrm{~g}$ culture biomass $\left(10^{9}\right.$ cells of microorganisms) were added to the flasks. The contents of the flasks were stirred on a shaker for $75 \mathrm{~min}^{-1}$ at a temperature of $18{ }^{\circ} \mathrm{C}$ for $30 \mathrm{~min}$. The average number of cells in one flask was $10^{7}$ per $1 \mathrm{~g}$ of sorbent. Enterosgel preparations and Sillard P dry powder were used as a sorbent. Enterosgel is a methyl-silicic acid hydrogel, a gel-like mass of white colour, odourless and tasteless, insoluble in water. Production of PJSC EOF "KREOMA-PHARM". Sillard P is a highly dispersed nanosilica produced at the Chuiko Institute of Surface Chemistry NAS of Ukraine, white powder of silica nature. It has no smell or taste. Miscible with water in any proportions.

\section{Analysis of samples}

The obtained samples were examined under a microscope with staining gentian violet, using a binocular microscope Motic (Fischer Bioblock) with a built-in video camera Top View 1000 for magnification x400 and AXIO Observer A1M of Carl Zeiss company for magnification x 1000 .

\section{Freeze-drying conditions}

For freeze-drying, pure cultures (control) and immobilized cells were mixed in a ratio of 1: 2 with sterile protective medium containing $10 \%$ sucrose, $5 \%$ sodium citrate, $5 \%$ skimmed milk powder and poured into vials of $1 \mathrm{~cm}^{3}$. Freeze-drying was performed on a freeze-dryer TG15 under the following modes: initial temperature minus $(60 \pm 2){ }^{\circ} \mathrm{C}$, final - plus $(30 \pm 2){ }^{\circ} \mathrm{C}$, residual pressure not more than $13.3 \cdot 10^{3} \mathrm{~Pa}$. Drying time from 24 to 28 hours.

\section{Survival rate of cultures}

To assess survival the number of cells in the obtained preparations by dilution and seeding on MPC agar before and after freeze-drying was determined.

\section{Characteristics of fermented milk clots}

Rheological characteristics of fermented milk clots (effective viscosity of practically intact structure, effective viscosity of extremely destroyed structure at maximum shear stress, effective viscosity of restored structure in conditions of reducing destructive force) were determined on a rotary viscometer "RHEOTEST II" with measuring system - cylinder ( $\mathrm{S} / \mathrm{S}_{3}$ ) (Kosoy, et al., 2010).

In the gap between the cylinders made $30 \mathrm{~cm}^{3}$ the clot, in which under the action of the force of rotation of the rotor there was a shift of one layer of the clot relative to another. The rheological characteristics of the product were determined by the speed of rotation of the rotor and the force of resistance to its rotation. Measurements were performed starting from low deformation rates. The indicators of the device were translated into stress shear $(\mathrm{Pa})$ at a given strain rate according to the formula: $\tau=\mathrm{Z} \times \alpha$, where $\tau$ - shear stress, $10^{-1} \mathrm{~Pa} ; \alpha$ - indicators of the device; $\mathrm{Z}$ - constant of the cylinder, $10^{-1} \mathrm{~Pa} /$ unit. of device scales. For $\mathrm{S} /$ $\mathrm{S}_{3}, \mathrm{Z}$ is $7.7510^{-1} \mathrm{~Pa} /$ unit.

The effective viscosity of the experimental samples was determined by the formula: $\eta_{\mathrm{ef}}=\left(\tau / \mathrm{D}_{\mathrm{r}}\right) \times 100$, where $\eta_{\mathrm{ef}}$ - effective viscosity, $\mathrm{mPa} \cdot \mathrm{s} ; \tau$ - shear stress, $\mathrm{Pa} ; \mathrm{D}_{\mathrm{r}^{-}}$shear rate $\mathrm{s}^{-1} ; \mathrm{D}_{\mathrm{r}}=$ const for each mode of clot destruction.

The relative angular velocity of the inner cylinder was calculated by the formula: $\omega=2 \times \pi \times R_{\text {in }} \times N$, where $\omega$ - the relative angular velocity, $m / s ; R_{i n}-$ radius of the inner cylinder; $\mathrm{N}$ - the rotor speed, $\mathrm{c}^{-1}$.

The curve of dependence of effective viscosity on angular velocity is described by the equation: $\eta_{\mathrm{ef}}=\mathrm{B} \times \omega^{-\mathrm{m}}$, where $\mathrm{B}$ - the factor equal to the value of effective viscosity at the circular speed of $1 \mathrm{~m} / \mathrm{s}$; $\mathrm{m}$ - intensity of destruction of the structure of the experimental material.

The thixotropic properties of clots were determined by the effective viscosity of the intact clot of fermented milk (Kosoy, et al., 2010).

Moisture retention capacity - according to the degree of syneresis (Shidlovskaya, 2004).

\section{Sensitivity to the model of gastric juice}

The study of sensitivity to the model of gastric juice was carried out according to the method (Boke, et al., 2010). Hydrochloric acid solutions with a $\mathrm{pH}$ of 2.0 were used as a model of gastric juice. Immobilized and 12-hour native cells of lactic acid bacteria and bifidobacteria were acidified with hydrochloric acid to $\mathrm{pH}$ 2.0 and kept under constant stirring in a thermostat at $37{ }^{\circ} \mathrm{C}$ for 5 hours Immediately after acidification, after 1,2 and 3 hours of exposure, samples were taken for analysis of the number of microorganisms. This model mimics the conditions created in the stomach.

\section{Functional properties}

To determine the functional state of the probiotic culture of $S$. thermophilus immobilized on the methyl silicic acid hydrogel, according to the biotechnological parameters of fermented milk yoghurt obtained on the basis of these cultures, a dairy product was prepared using dry non-and immobilized cultures. Milk with a fat content of $2.5 \%$ was pasteurized at $86^{\circ} \mathrm{C}$ for 20 minutes, cooled to a fermentation temperature of $37^{\circ} \mathrm{C}$ and introduced non immobilized and immobilized strain of $S$. thermophilus in the amount of $1 \mathrm{~g} / 1$ Fermentation was performed until the products in the titratable acidity of $70^{\circ} \mathrm{T}$.

\section{RESULTS AND DISCUSSION}

Digital microimages of preparations $S$. thermophilus after sorption and after freeze-drying are shown in Fig. 1.

As can be seen from the photo, the cells of microorganisms with a powder sorbent (Sillard P) are grouped around the sorbent particles aggregates, which indicates the immobilization of probiotic cultures on a highly dispersed silicon preparation. Microscopic studies revealed a high sorbent capacity of $\mathrm{SiO}_{2}$ nanopowder aggregates. Almost all cells of $S$. thermophilus in suspension join the aggregates of nanopowder Sillard P (Fig.1).

The drug obtained on the basis of methyl-silicic acid hydrogel (Enterosgel) has another form. The cells seem to be included in the structure of the gel and dry with it.

Thus, it is possible to immobilize cells using a suspension of aggregates of nanopowder $\mathrm{SiO}_{2}$ and methyl-silicic acid hydrogel, the surface of which largely retains the properties of the nanostructured material.

Preparations of cultures of B. longum and S. thermophilus, obtained after immobilization on powder sorbent and methyl-silicic acid hydrogels and after freeze-drying, were tested for survival.

For the convenience of representation of samples in the table and the diagram samples are ciphered (Tab. 1).

It is shown that the viability of free cells of B. longum and S. thermophilus in the process of freeze-drying is influenced by the type of sorbent (Tab. 2).

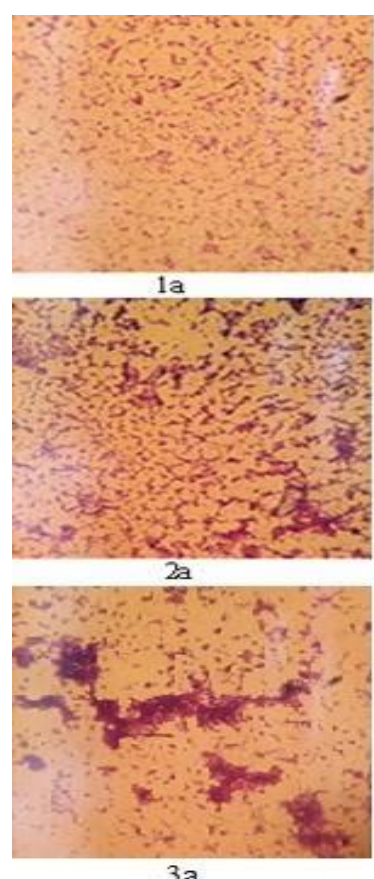

$3 a$

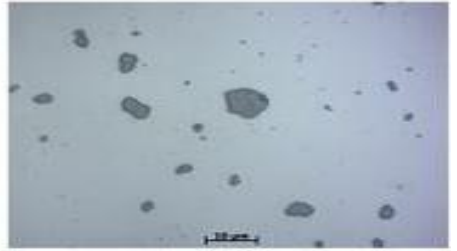

$1 \mathrm{~b}$

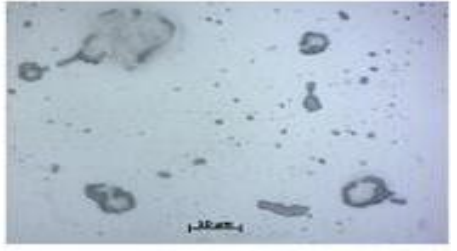

$2 \mathrm{~b}$

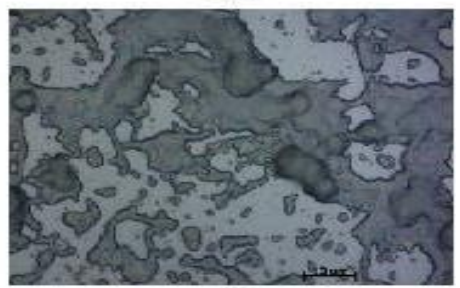

$3 \mathrm{~b}$
Figure 1 Digital microimages of preparations $S$. thermophilus after sorption and after freeze-drying: (1a) - control: suspension, x400, (1b) - control: freeze-dried drug, x1000; (2a) - suspension after immobilization on nanopowder $\mathrm{SiO}_{2}, \mathrm{x} 400$ (2b) - freeze-dried complex, x1000; (3a) - suspension after immobilization in a hydrogel of methyl-silicic acid, x400, (3b) - freeze-dried complex, x1000. 
Table 1 Designation of the experimental sample.

\begin{tabular}{|c|c|}
\hline $\begin{array}{l}\text { Designation of the } \\
\text { sample }\end{array}$ & Sample of the description \\
\hline E1 & Culture B. longum (control) \\
\hline $\mathbf{E 2}$ & $\begin{array}{c}\text { Culture } B \text {. longum, immobilized on a methyl-silicic } \\
\text { acid hydrogel }\end{array}$ \\
\hline $\mathbf{E 3}$ & $\begin{array}{c}\text { Culture } B . \text { longum, immobilized on } \mathrm{SiO}_{2} \\
\text { nanopowder }\end{array}$ \\
\hline E4 & Culture $S$ thermophilus (control) \\
\hline $\mathbf{E 5}$ & $\begin{array}{l}\text { Culture of } S \text {. thermophilus immobilized on a methyl- } \\
\text { silicic acid hydrogel }\end{array}$ \\
\hline E6 & $\begin{array}{c}\text { Culture of } S . \text { thermophilus immobilized on a } \mathrm{SiO}_{2} \\
\text { nanopowder }\end{array}$ \\
\hline
\end{tabular}

Table 2 Survival of free and immobilized cultures in the process of freezedrying.

\begin{tabular}{lcc}
\hline Type of material & $\begin{array}{c}\text { Biomass before } \\
\text { freeze-drying, lg N, } \\
\text { CFU / g }\end{array}$ & $\begin{array}{c}\text { Biomass after freeze-drying, } \\
\text { lg N, CFU/g }\end{array}$ \\
\hline E1 & $9.8 \pm 0.3$ & $9.6 \pm 0.3$ \\
\hline E2 & $8.6 \pm 0.2$ & $7.6 \pm 0.2$ \\
\hline E3 & $9.4 \pm 0.3$ & $6.8 \pm 0.2$ \\
\hline E4 & $8.8 \pm 0.1$ & $7.5 \pm 0.3$ \\
\hline E5 & $9.3 \pm 0.3$ & $9.1 \pm 0.1$ \\
\hline E6 & $9.0 \pm 0.3$ & $6.2 \pm 0.3$ \\
\hline
\end{tabular}

The preservation of sorbent complexes with cells by freeze-drying was significantly lower than the viability of free cells with a protective medium.

The percentage of preserved free cells of $S$. thermophilus and B. longum after freeze-drying was quite high, the survival of bacteria reached the level of $(97 \div$ 98)\%.

The survival of immobilized cells on the methyl-silicic acid hydrogel after freeze-drying was reduced by an order of magnitude, while on the finely divided dry powder - by 2 orders of magnitude. Therefore, it was found that immobilization on methyl-silicic acid hydrogel caused less cell death than on dry finely divided powder.

For probiotics used orally, the ability to maintain viability during transit through the upper digestive tract to the site of their main location - the large intestine - is important. In this way, the microbiota must overcome such barriers as high acidity of gastric juice, the action of digestive enzymes and the destructive action of bile. It is now known that during the transit of exogenous microflora through the stomach and small intestine, about $60-70 \%$ of viable cells of microorganisms are lost. Therefore, it is very important to include in the composition of probiotics microorganisms that are resistant to these factors or to protect cells.

Evaluation of acid resistance of pure and immobilized in the hydrogel of methylsilicic acid cultures was performed in vitro. To do this, each of the cultures was kept in solutions of hydrochloric acid $(\mathrm{pH} 2.0)$ for $1-3$ hours.
The resistance of strains was determined by the number of bacterial cells that retained their viability after exposure to these conditions.

The results of modelling the intestinal conditions are shown in Fig. 2.

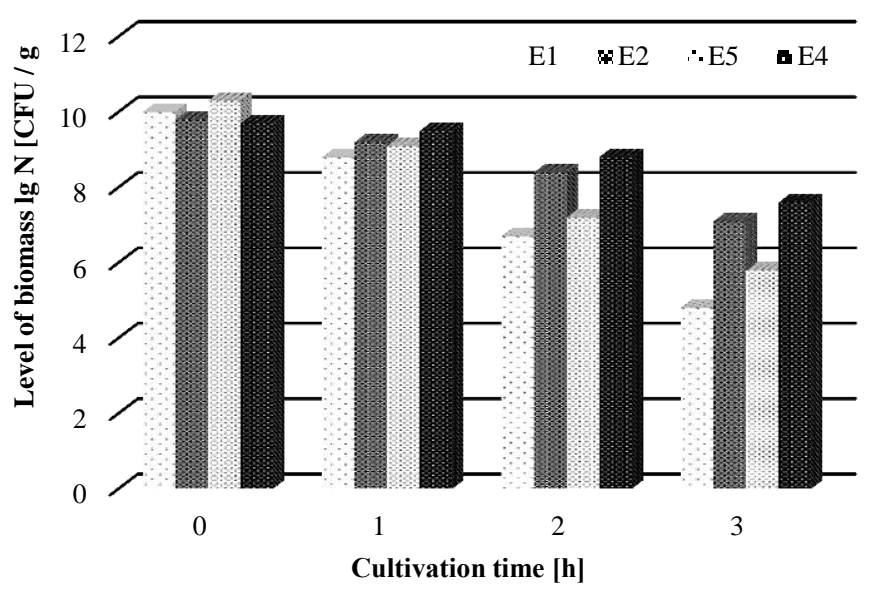

Figure 2 The number of cells of free and immobilized lacto- and bifidobacteria at different durations of exposure with $\mathrm{pH} 2$ (E1, E2, E4, E5 are shown in Tab. 2)

During the period of action that modulates the conditions in the stomach observed a rapid decrease in the number of free cells of bacteria $S$. thermophilus and B. longum. After $3 \mathrm{~h}$, the number of viable cells B.longum decreased from $\mathrm{lg}$ 10 to $\lg 4.8, S$. thermophilus - from $\lg 10.3$ to $\lg 5.8$. At the same time, for cells immobilized in the methyl-silicic acid hydrogel, a gradual decrease to $\lg 7.1$ was observed. Immobilized cells $S$. thermophilus were less exposed to $\mathrm{pH}$, their number decreased by only 2.1 orders of magnitude. From the results, we can conclude that immobilization in the hydrogel of methyl-silicic acid increases cell survival. Similar results were also observed in the study (Afzaal, et al., 2018).

Thus, the studied immobilized strains of lacto- and bifidobacteria showed high resistance to low $\mathrm{pH}$ values, which contributes to their survival in the upper gastrointestinal tract, i.e immobilization has a protective effect in the simulated conditions.

Functional state of immobilized culture cells $S$. thermophilus was studied for rheological and biotechnological parameters, such as effective viscosity, moisture retention capacity, thixotropy, fermentation duration, active acidity, etc. (Fig. 3-4, Table 3-4).

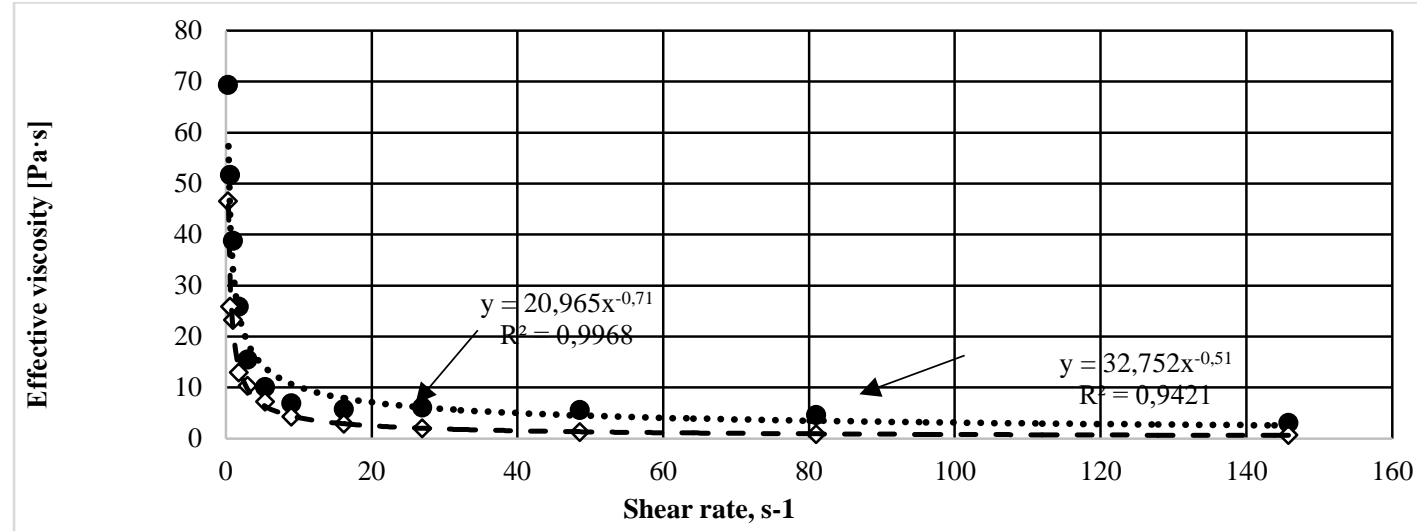

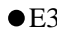

$\diamond \mathrm{E} 4$

Figure 3 Curves of fluidity of the destruction of a clot of fermented milk by the free and immobilized culture of S. thermophilus (E5, E4 are shown in Tab. 1)

Fig. 3 shows that the effective viscosity in the strain of S. thermophilus in the case of increasing stress decreases faster, while in the strains of immobilized later. The latter have high strength. Therefore, it can be assumed that immobilized cultures are more resistant to mechanical impact.

Tab. 3 shows the value of the effective viscosity of mature fermented milk clots and their moisture-holding capacity.

Thus, immobilization of culture allows changing texture of products - effective viscosity of fermented products due to the immobilized culture of $S$. thermophilus increased by (12.1-27.9) \%.
Table 3 Structural and mechanical parameters of mature clots obtained by immobilized and non-immobilized cultures of S. thermophilus.

\begin{tabular}{lcc}
\hline Sample & Effective viscosity, mPa s & Moisture holding capacity, \% \\
\hline E1 & $23,3 \pm 1,2$ & 72 \\
E2 & $32,4 \pm 1,4$ & 94 \\
E5 & $21,1 \pm 1,2$ & 75 \\
E4 & $24,2 \pm 0,8$ & 73 \\
\hline
\end{tabular}

The visible manifestation of thixotropy is characterized by the dependence of the effective viscosity on the deformation gradient with increasing shear rate and subsequent its reduction. 
From the obtained data, curves of fluidity were constructed in the range of increase and decrease of the deformation rate from 0.33 to $145.80 \mathrm{~s}^{-1}$ of a clot of milk fermented by immobilized and non-immobilized cultures. The obtained graphical dependences of shear stress $(\tau)$ on the shear rate $(\gamma)$ of clots are given in Fig. 4.
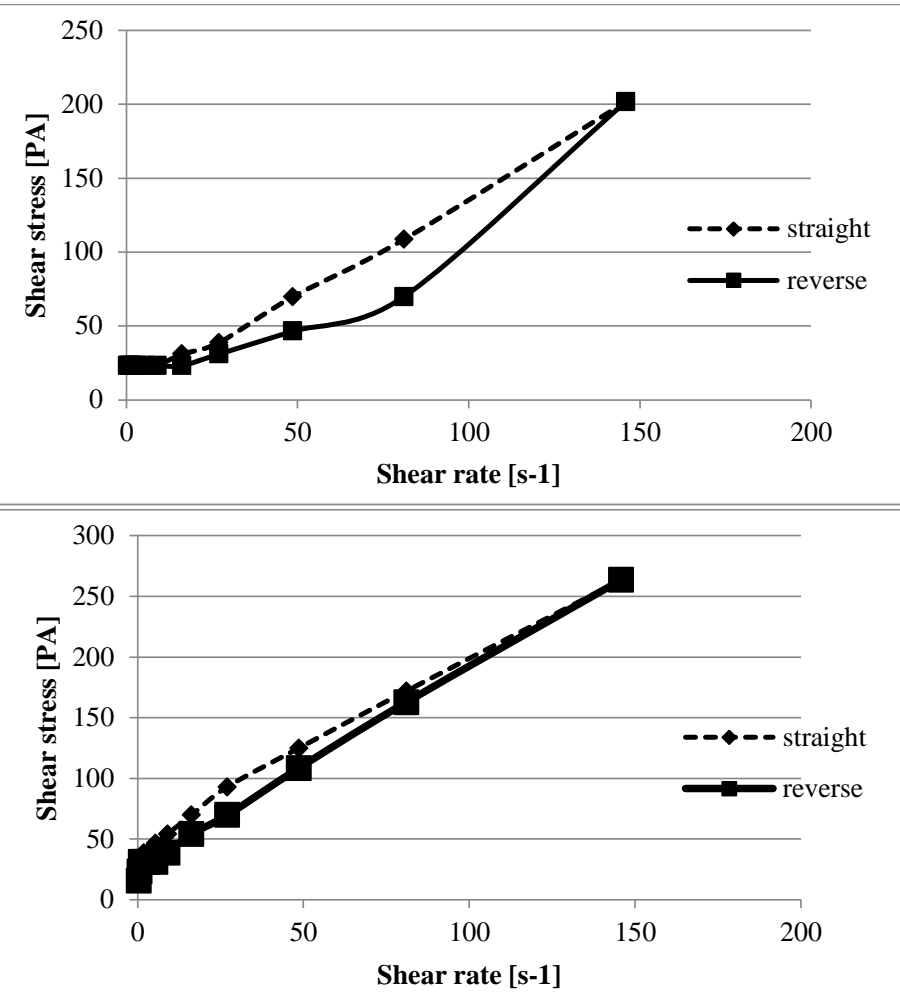

Figure 4 Curves of the fluidity of a clot of fermented milk (a) used not immobilized S. thermophilus culture; (b) used immobilized S. thermophilus culture.

It is shown that the width of the "hysteresis loop" of the curves of the yield of fermented milk clot taken for the experiment of immobilized and nonimmobilized culture $S$. thermophilus is different. This is due to the fact that these cultures form a clot with a viscous and plastic consistency. Analysis of the rheological characteristics of the clots showed that the samples fermented with immobilized cultures have a greater ability to restore the structure and provide stability of the structure of fermented milk clots during storage.

Table 4 Characteristics of the biotechnological properties of fermented milk product fermented by immobilized and non-immobilized culture S.thermophilus

\begin{tabular}{ll} 
Indicator & Indicator value dairy products, sour \\
\cline { 2 - 3 } & Sourdough is not immobilized Immobilized culture
\end{tabular}

\begin{tabular}{|c|c|c|}
\hline & S. thermophilus & S. thermophilus \\
\hline $\begin{array}{l}\text { Development in the } \\
\text { presence of } 30 \% \text { bile }\end{array}$ & 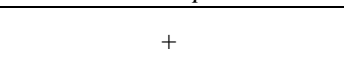 & + \\
\hline $\begin{array}{l}\text { Development in the } \\
\text { presence of } 6.5 \% \mathrm{NaCl}\end{array}$ & + & + \\
\hline $\begin{array}{l}\text { Duration of fermentation } \\
\text { of milk at a dosage of } 1 \\
\mathrm{~g} / \mathrm{L}, \mathrm{h}\end{array}$ & $6,5-7,0$ & $8-9$ \\
\hline $\begin{array}{l}\text { Maximum acidity in } \\
\text { fermented milk, }{ }^{\circ} \mathrm{T}\end{array}$ & $100 \pm 5$ & $95 \pm 5$ \\
\hline $\begin{array}{l}\text { Active acidity in } \\
\text { fermented milk after } 14 \\
\text { days of storage, units } \mathrm{pH}\end{array}$ & $4.3 \pm 0.1$ & $4.7 \pm 0.1$ \\
\hline $\begin{array}{l}\text { Effective viscosity of } \\
\text { sour milk clot at a } \\
\text { temperature of } 20^{\circ} \mathrm{C} \text {, } \\
\mathrm{mPa} \cdot \mathrm{s}\end{array}$ & $23.3 \pm 1.2$ & $32.4 \pm 1.4$ \\
\hline
\end{tabular}

Therefore, the structural and mechanical characteristics of clots of milk fermented by immobilized culture were better compared to non-immobilized cultures. The clots were more resistant to mechanical damage and had high thixotropy.

\section{CONCLUSIONS}

Thus, for the creation of complex enterosorbent-probiotic preparations, it is possible to immobilize lacto- and bifidobacterial cells on highly dispersed silica in the form of $\mathrm{SiO}_{2}$ nanopowder and methyl silicic acid hydrogel.

Photomicrographs of such drugs showed that the cells accumulate on the surface of nano- $\mathrm{SiO}_{2}$ aggregates and penetrate into the hydrogel structure. Survival of lyophilized control drugs was better than drugs immobilizated in the hydrogel structure. But immobilization of probiotic cultures of B. longum and St. thermophilus in the hydrogel provided better resistance of these cultures to the conditions of the gastrointestinal tract: after $3 \mathrm{~h}$ the number of viable cells $B$ longum decreased by 4-5 orders of magnitude, while for cells immobilized in methyl silicic acid hydrogel, a decrease in survival by 2-3 orders of magnitude was observed.

The preparation of immobilized in hydrogel culture $S$. thermophilus allows increasing the effective viscosity with the help of fermented products by (12.1 $27.9) \%$. The clots were more resistant to mechanical damage and had high thixotropy.

The method of immobilization provides the required level $\left(10^{7}-10^{8} \mathrm{CFU} / \mathrm{g}\right)$ of probiotic cultures in the product. Biotechnological parameters of fermented milk yoghurt based on $S$. thermophilus confirmed that the culture after sorption on Enterosgel remained quite functional, although the duration of milk fermentation increased by 2-2.5 hours.

\section{REFERENCES}

Afzaal, M., Saeed, F., Arshad, M. U., Nadeem, M. T., Saeed, M., \& Tufail, T. (2018). The Effect of Encapsulation on The Stability of Probiotic Bacteria in Ice Cream and Simulated Gastrointestinal Conditions. Probiotics and Antimicrobial Proteins, 11(4), 1348-1354. https://doi.org/10.1007/s12602-018-9485-9

Babinets, O. M. (2012). Correction of dysbiosis by preparations of probiotics immobilized on enterosorbents after their low-temperature storage. Visnyk Problem Biologii i Meditsyny, 1 .

Boke, H., Aslim, B., \& Alp, G. (2010). The role of resistance to bile salts and acid tolerance of exopolysaccharides (EPSS) produced by yogurt starter bacteria. $\begin{array}{llll}\text { Archives of } \quad \text { Biological } & \text { Sciences, } & 62,\end{array}$ https://doi.org/10.2298/abs1002323b

Dalal, N. S., Shi, X., \& Vallyathan, V. (1990, 3). Role of free radicals in the mechanisms of hemolysis and lipid peroxidation by silica: Comparative ESR and cytotoxicity studies. Journal of Toxicology and Environmental Health, 29, 307 316. https://doi.org/10.1080/15287399009531393

Diab, R., Canilho, N., Pavel, I. A., Haffner, F. B., Girardon, M., \& Pasc, A. $(2017,11)$. Silica-based systems for oral delivery of drugs, macromolecules and cells. Advances in Colloid and Interface Science, 249, 346-362. https://doi.org/10.1016/j.cis.2017.04.005

Florek, J., Caillard, R., \& Kleitz, F. (2017). Evaluation of mesoporous silica nanoparticles for oral drug delivery - current status and perspective of MSNs drug carriers. Nanoscale, 9, 15252-15277. https://doi.org/10.1039/c7nr05762h

Fubini, B. (1998). Health effects of silica. The surface properties of silicas, 415 464

Nolan, R. P., \& Langer, A. M. (1997). Physico-chemical Properties of Inorganic Particles Controlling Biological Activity. Carcinogenicity of Inorganic Substances, 39-57. https://doi.org/10.1016/b978-1-85573-800-3.50009-0

Voronin, E. P., Nosach, L. V., Pakhlov, E. M., Gunko, V. M., Chekman, I. S., Rudenko, A. V., . . . \& Terpilowski, K. (2016). Creation of stable aqueous dispersions of nanosilica as an enterosorbent. Surface, 8(23), 267-283. https://doi.org/10.15407/surface.2016.08.267

Gerashchenko, I.I. (2009). Membranotropic properties of nanoscale silica. Surface, 16, 288-306.

Gorbyk, P.P., Pentyuk, O.I., Shtatko, O.O. (2008). Prospects for the establishment of combiogenic varieties of drugs on the basis of visocodisperse silica. Nanosystems, nanomateriali, nanotechnology, 6, 315-330.

Kosoy, V. D., Dunchenko, N. I, \& Merkulov, M. Y (2010). Dairy products rheology (full course) (theory, scientific research, reference material, laboratory workshop).

Leonenko N.S., Leonenko O.B. (2020). Factors influencing the manifestation of toxicity and danger of nanomaterials. Innov Biosyst Bioeng, 4(2), 75-88. https://doi.org/10.20535/ibb.2020.4.2.192810

Shidlovskaya, V. P. (2004). Organoleptic properties of milk and dairy products Moscow: Colossus. 